\title{
ERRATUM
}

Daolin Fu • Péter Szúcs • Liuling Yan

Marcelo Helguera $\cdot$ Jeffrey S. Skinner Jarislav von Zitzewitz $\cdot$ Patrick M. Hayes Jorge Dubcovsky

\section{Large deletions within the first intron in VRN-1 are associated with spring growth habit in barley and wheat}

Published online: 22 October 2005

(C) Springer-Verlag 2005

\section{Molecular Genetics and Genomics 273(1):54-65}

The version of Table 2 that appeared in this paper contained a number of errors. The correct version appears below:

The online version of the original article can be found at http:// dx.doi.org/10.1007/s00438-004-1095-4

D. Fu $\cdot$ L. Yan · J. Dubcovsky ( $₫)$

Department of Plant Sciences, University of California,

One Shields Av, Davis, CA 95616, USA

E-mail: jdubcovsky@ucdavis.edu

P. Szücs

Agricultural Research Institute of the Hungarian Academy of Sciences, 2462 Martonvásár, Hungary

M. Helguera

EEA INTA Marcos Juárez, CC 21, 2580 Marcos Juárez,

Argentina

J. S. Skinner · J. von Zitzewitz · P. M. Hayes

Department of Crop and Soil Science and Horticulture,

Oregon State University, Corvallis, OR 97331, USA 


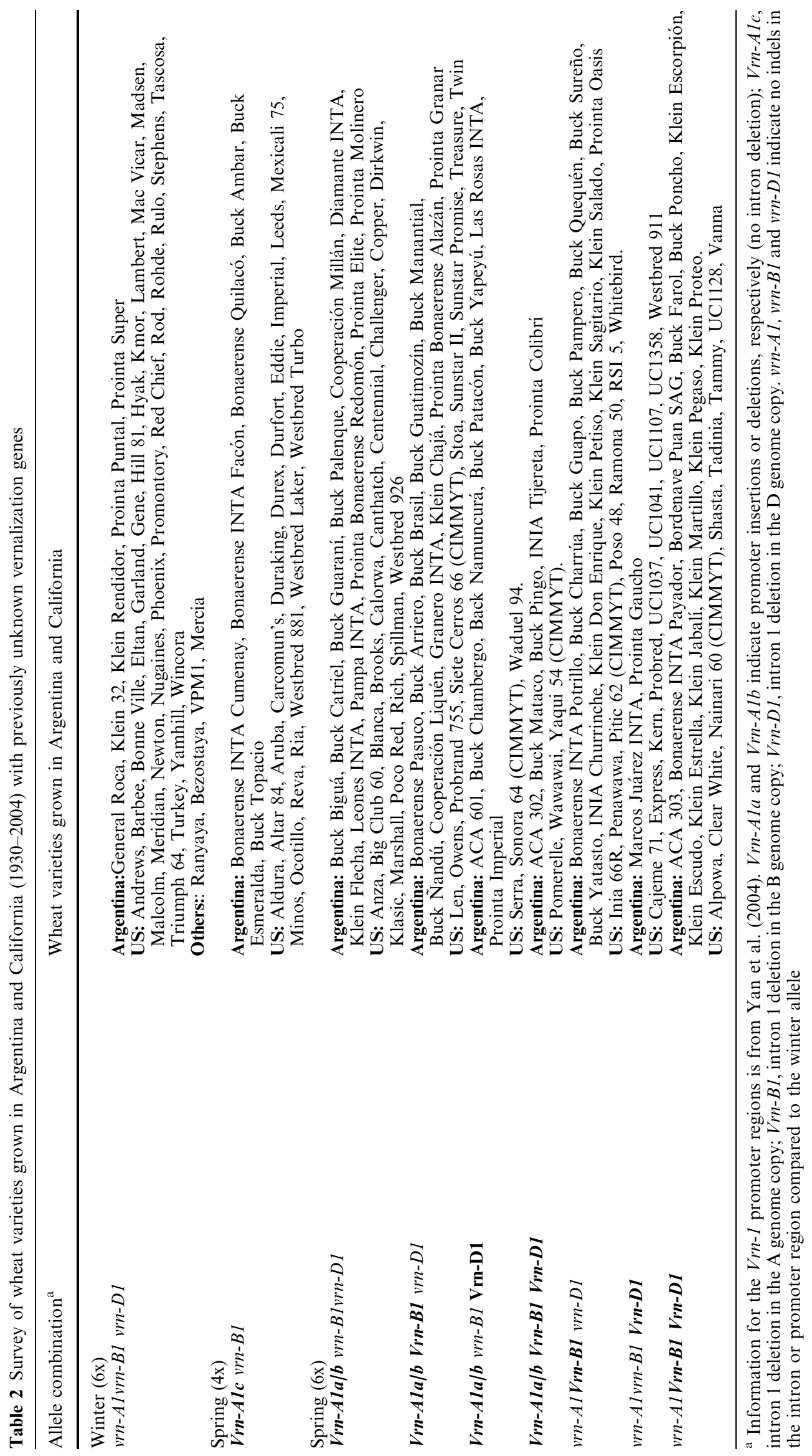

